\title{
Upaya Penanganan dan Perilaku Pasien Penderita Diabetes Mellitus Tipe 2 Di Puskesmas Bara-Baraya Kota Makassar
}

\author{
Ismi Irfiyanti Fachruddin ${ }^{1}$, Citrakesumasari ${ }^{2}$, Sri'ah Alharini' ${ }^{2}$ \\ ${ }^{1}$ Program Studi Gizi Universitas Megarezky, Makassar, Indonesia \\ ${ }^{2}$ Program Studi Ilmu Gizi Fakultas Kesehatan Masyarakat Universitas Hasanuddin Makassar \\ Alamat: Program Studi Gizi Universitas Megarezky, Jl. Antang Raya No. 43, Kota Makassar, Sulawesi Selatan \\ Korespondensi E-mail: ismi.irfiyanti@gmail.com
}

Submitted: 01 November 2020, Revised: 10 April 2021, Accepted: 20 April 2021

\begin{abstract}
The prevalence of DM is getting higher in developed and developing country, such as Indonesia. DM occupied the fifth rank from ten main causes of death in Makassar 2007. The aim of this study is to identify the treatment and behaviour of patients of DM type 2 at Bara-Baraya Health Center Makassar in 2013. The design study was cross-sectional study from 13th March - 13th April. There are 2 kinds of samples in this research, health officers and patients of DM type 2. The sampling echnique used purposive sampling. The treatment was evaluated by observation. The inclusion criteria were patients of DM type 2 at Bara-Baraya Health Center with no compliation. Patient's behaviour was collected by direct interview, including characteristic of the patients, anthropometry (body weight and height), knowledge of DM, food recall 24 hours, physical activity, and intervention of DM type 2 medicine. The results showed caring effort of DM based on the pillar of handling DM were still lacking (all patients did not get DM education), knowledge of type $2 \mathrm{DM}$ patients was still lacking (71.9\%), non-compliance with the number of calories (78.1\%), lack of physical activity (53.1\%), non-compliance with taking medication (56.2\%), and uncontrolled blood glucose (56.2\%). This research recommended to maximize the role of health of TPG in service in POZI. In addition, it's better that the service in POZI in not only for the babies or pregnant women, but also functional to serve other patients, especially for DM patients.
\end{abstract}

Keyword: Diabetes Mellitus, Effort of Caring DM, Clinic, Behaviour

\begin{abstract}
Abstrak
Prevalensi diabetes mellitus semakin tinggi baik di negara-negara maju maupun di negara-negara berkembang seperti Indonesia. Diabetes mellitus menempati peringkat lima dari sepuluh penyebab utama kematian di Makassar tahun 2007. Penelitian ini bertujuan untuk mengetahui upaya penanganan dan perilaku pasien penderita diabetes mellitus tipe 2 di Puskesmas Bara-Baraya Kota Makassar tahun 2013. Desain penelitian menggunakan survey cross-sectional yang dilakukan pada bulan Maret-April 2013 dengan jumlah sampel 32 orang. Sampel dalam penelitian ini ada dua, yaitu petugas kesehatan dan pasien diabetes mellitus tipe 2. Teknik pengambilan sampel yaitu purposive sampling. Tindakan penanganan dievaluasi melalui pengamatan. Kriteria inklusi adalah pasien DM tipe 2 Puskesmas Bara-Baraya dan tidak mengalami komplikasi. Penelitian terhadap perilaku pasien dilakukan melalui wawancara langsung terhadap pasien, meliputi karakteristik pasien, pengukuran antropometri (BB, TB), pengetahuan, food recall $24 \mathrm{jam}$, aktivitas fisik, dan data monitoring konsumsi obat DM. Analisis dilakukan terhadap tiap variabel dari hasil penelitian dengan menggunakan tabel distribusi frekuensi sehingga menghasilkan distribusi dan persentase dari setiap variabel. Hasil penelitian didapatkan upaya penanganan5555559+ DM berdasarkan pilar penanganan DM masih kurang (semua pasien tidak mendapatkan Edukasi DM), pengetahuan pasien DM tipe 2 masih kurang $(71,9) \%$, tidak patuh jumlah kalori $(78,1 \%)$, aktivitas fisik kurang $(53,1 \%)$, tidak patuh minum obat (56,2\%), serta glukosa darah tidak terkontrol (56,2\%). Penelitian ini merekomendasikan untuk lebih memaksimalkan peran tenaga pekerja gizi dalam pelayanan di pojok gizi. Sebaiknya pelayanan di pojok gizi tidak hanya diperuntukkan untuk bayi, balita ataupun ibu hamil saja, tetapi juga difungsikan untuk melayani pasien penderita penyakit lain, khususnya pasien penderita DM.
\end{abstract}

Kata Kunci: Diabetes Mellitus, Pilar Penanganan DM, Puskesmas, Perilaku

\section{Pendahuluan}

Menurut WHO, terdapat 422 juta orang yang menderita Diabetes Mellitus, terutama di negara berpenghasilan rendah dan menengah, dan sebanyak 30,3 juta penduduk di Amerika Serikat mengalami DM(1). Laporan dari International Diabetes Federation (IDF) 2017, memprediksi adanya kenaikan jumlah penderita DM di dunia dari 425 juta jiwa pada tahun 2017, menjadi 629 juta jiwa pada tahun 2045. Sedangkan di Asia Tenggara, dari 82 juta pada tahun 2017, menjadi 151 juta pada tahun 2045. 
Indonesia merupakan negara ke-7 dari 10 besar negara yang diperkirakan memiliki jumlah penderita DM sebesar 5,4 juta pada tahun 2045 serta memiliki angka kendali kadar gula darah yang rendah (2). Laporan hasil Riset Kesehatan Dasar (Riskesdas) Departemen Kesehatan Republik Indonesia 2013, menunjukkan bahwa rata-rata prevalensi DM di masing-masing provinsi Indonesia berdasarkan diagnosis dokter dari penduduk umur $\geq 15$ tahun pada tahun 2013 mencapai 1,5\%, dan meningkat pada tahun 2018 mencapai 2\%. Prevalensi terkecil terdapat di Nusa Tenggara Timur sebesar 0,9\%, sedangkan prevalensi terbesar terdapat di Daerah Khusus Ibukota (DKI) Jakarta sebesar 3,4\% (3). Prevalensi DM berdasarkan pemeriksaan darah dari penduduk umur $\geq 15$ tahun dengan konsensus Perkumpulan Endokrinologi Indonesia (Perkeni) 2011 pada tahun 2013 mencapai 6,9\%, dan meningkat pada tahun 2018 mencapai 8,5\%. Sedangkan prevalensi DM berdasarkan pemeriksaan darah dari penduduk umur $\geq 15$ tahun dengan konsensus Perkeni 2015 mencapai 10,9\% pada tahun 208(4). Berdasarkan surveilans rutin penyakit tidak menular berbasis rumah sakit di Sulawesi Selatan tahun 2008, DM termasuk dalam urutan keempat penyakit tidak menular (PTM) terbanyak yaitu sebesar 6,65\% dan urutan kelima terbesar PTM penyebab kematian yaitu sebesar 6,28\%. Bahkan pada tahun 2010, DM menjadi penyebab kematian tertinggi PTM di Sulawesi Selatan yaitu sebesar 41,56\% (5) Peningkatan kasus DM juga terjadi ditingkat kabupaten/kota, khususnya di Kota Makassar. Diabetes mellitus menempati peringkat lima dari sepuluh penyebab utama kematian di Makassar tahun 2007 dengan jumlah sebanyak 65 kasus. Berdasarkan data dari Dinas Kesehatan Kota Makassar, angka kejadian penyakit diabetes mellitus pada tahun 2011 yaitu 5700 kasus. Pada tahun 2012 angka kejadian kasus DM meningkat menjadi 7000 kasus (6).

Dalam mengelola diabetes mellitus langkah pertama yang harus dilakukan adalah pengelolaan non farmakologis, berupa perencanaan makan dan kegiatan jasmani. Baru kemudian kalau dengan langkah-langkah tersebut sasaran pengendalian diabetes yang ditentukan belum tercapai, dilanjutkan dengan langkah berikut, yaitu penggunaan obat/pengelolaan farmakologis. Menurut konsensus Perkumpulan Endokrinologi Indonesia (Perkeni), penanganan diabetes melitus pada dasarnya terdiri atas 4 (empat) pilar penatalaksanaan/pengelolaan diet diabetes melitus, yaitu edukasi/penyuluhan, perencanaan makan, latihan jasmani atau exercise dan intervensi farmakologis (obat $\mathrm{OHO}$ (7). Sumber daya manusia di pusat pelayanan kesehatan strata pertama merupakan factor penting dalam keberhasilan program penatalaksanaan DM (8). Beberapa hasil penelitian menunjukkan, pengetahuan, diet, dan aktivitas fisik sebelum dan setelah edukasi gizi mengalami peningkatan. $(9,10,11,12,13,14)$. Penelitian membuktikan bahwa penatalaksanaan DM secara optimal akan dapat meningkatkan kualitas hidup baik untuk jangka pendek maupun jangka panjang, dimana sumber daya manusia di pusat pelayanan strata pertama merupakan faktor penting dalam keberhasilan penatalaksanaan program DM.

Di Kota Makassar, Kecamatan Makassar merupakan kecamatan yang memiliki kepadatan penduduk tertinggi. Puskesmas Bara-Baraya merupaka Puskesmas yang berada di wilayaha Kec. Makassar. Berdasarkan data Puskesmas Bara-baraya, prevalensi kasus DM di wilayah tersebut terus mengalami peningkatan, 326 kasus pada tahun 2010, 351 kasus pada tahun 2011, dan 380 kasus pada tahun 2012. Dari 380 kasus pada tahun 2012, didapatkan sebanyak 69.47\% penderita DM memiliki glukosa darah tidak terkontrol. Berdasarkan latar belakang di atas, peneliti tertarik untuk melakukan penelitian mengenai upaya penanganan yang dilakukan Puskesmas Bara-Baraya untuk mencegah terjadinya peningkatan kasus DM, serta mengetahui bagaimana perilaku pasien penderita diabetes mellitus tipe 2 di Puskesmas Bara-Baraya Kota Makassar tahun 2013.

\section{Metode Penelitian}

Adapun lokasi penelitian ini dilaksanakan di Puskesmas Bara-Baraya Kota Makassar. Jenis penelitian yang digunakan adalah survei observasional deskriptif. Sebanyak 32 orang pasien DM yang datang memeriksakan kesehatan ke Puskesmas Bara-baraya pada bulan Maret-April 2013 menjadi sampel penelitian. Pengumpulan data mengenai upaya penanganan dilakukan dengan cara peneliti melakukan observasi langsung terhadap petugas kesehatan dengan menggunakan tabel observasi 4 Pilar penanganan DM. Dikategorikan cukup apabila menjelaskan 3 poin dari masing-masing pilar, dan dikategorikan kurang apabila menjelaskan kurang dari 3 pada masing-masing pilar. 
Tabel 1

Empat Pilar Penganan DM

\begin{tabular}{ll}
\hline & Empat Pilar Penanganan DM \\
\hline Pilar 1: Edukasi DM & Pengertian DM \\
& Faktor Risiko DM \\
& Komplikasi \\
\hline Pilar 2: Perencanaan Diet & Jumlah Kebutuhna Kalori \\
& Jadwal Makan \\
& Jenis bahan Makanan/Minuman yang dihindari \\
\hline Pilar 3: Aktivitas Fisik & Jenis Aktivitas Fisik \\
& Manfaat Aktivitas Fisik \\
& Frekuensi dan Durasi Aktivitas Fisik \\
\hline Pilar 4: Intervensi Obat & Cara minum obat DM \\
& Dosisi Obat DM \\
& Frekuensi Obat DM \\
\hline
\end{tabular}

Karakteristik pasien di peroleh dengan wawancara menggunakan kuesioner. Pengetahuan pasien DM di ukur berdasarkan kemampuannya mengulang kembali informasi yang telah diberikan oleh petugas kesehatan dengan menggunakan kuesioner ceklist 4 Pilar penanganan DM yang terdiri dari 12 nomor (kategori sangat sesuai, sesuai, tidak sesuai, tidak tahu). Sikap pasien DM adalah kecenderungan atau segala yang dianggap kebenarannya dan berdasarkan pengetahuan yang dimiliki pasien DM, diperoleh dengan menggunakan kuesioner sikap merujuk kepada 4 Pilar penanganan DM yang terdiri dari 8 nomor (kategori sangat setuju, setuju, tidak setuju, sangat tidak setuju). Pengukuran antropometri terhadap berat badan dan tinggi badan untuk memperoleh data kebutuhan kalori pasien DM. Wawancara Food recall 24 jam dilakukan untuk mengetahui jumlah kalori yang dikonsumsi pasien DM. Data aktivitas fisik dan konsumsi obat DM dilakukan dengan melakukan wawancara langsung kepada pasien dengan menggunakan lembar monitoring untuk mengetahui apakah dilakukan sesuai dengan anjuran yang diberikan oleh petugas kesehatan. Data sekunder berupa gambaran umum Puskesmas Bara-Baraya Kota Makassar yang diperoleh dari data profil Puskesmas Bara-Baraya dan data kadar glukosa darah diperoleh melalui buku rekam medik. Jenis analisis yang dilakukan yaitu analisis univariat. Analisis univariat dilakukan terhadap tiap variabel dari hasil penelitian dengan menggunakan tabel distribusi frekuensi sehingga menghasilkan distribusi dan persentase dari setiap variable. Penelitian ini telah disetujui oleh Dinas Kesehatan Kota Makasar dengan 070/30/DKK/III/2013.

\section{Hasil dan Pembahasan}

Tabel 2 menunjukkan bahwa jumlah pasien sebagian besar berjenis kelamin perempuan yaitu sebanyak 25 pasien (78,1\%). Jumlah penderita DM tipe 2 berdasarkan kelompok umur paling banyak terdapat pada kelompok umur $\geq 60$ tahun yaitu 16 pasien $(50,0 \%)$ dan kelompok umur paling sedikit menderita DM tipe 2 ada pada kelompok umur 31-44 tahun yaitu 3 pasien (9,4\%). Pada kelompok pekerjaan yang terbanyak yang menderita DM tipe 2 ada pada kelompok pekerjaan IRT (ibu rumah tangga) yaitu 23 pasien $(71,9 \%)$ dan paling sedikit yaitu pada kelompok lainnya sebanyak 2 pasien $(6,2$ $\%$. Menurut tingkat pendidikan, penderita terbanyak pada pendidikan dasar (SD) sebanyak 13 pasien $(40,6 \%)$ dan kelompok dengan tingkat pendidikan paling sedikit yaitu sarjana yaitu sebanyak 5 pasien $(15,6 \%)$. 
Tabel 2.

Distribusi Karakteristik Pasien Penderita Diabetes Mellitus Tipe 2 di Puskesmas Bara-Baraya Kota Makassar

\begin{tabular}{lcc}
\hline \multicolumn{1}{c}{ Karakteristik Umum } & $\mathbf{n}$ & $\mathbf{\%}$ \\
\hline Jenis Kelamin & & \\
Laki-laki & 7 & 21,9 \\
Perempuan & 25 & 78,1 \\
Kelompok Umur (Tahun) & & \\
31-44 & 3 & 9,4 \\
45-59 & 13 & 40,6 \\
$\geq 60$ & 16 & 50,0 \\
Pekerjaan & & \\
PNS & 4 & 12,5 \\
Pegawai Swasta & 3 & 9,4 \\
Lainnya/Pensiunan & 2 & 6,2 \\
IRT & 23 & 71,9 \\
Pendidikan & & \\
Pendidikan Dasar & 13 & 40,6 \\
SMP & 8 & 25,0 \\
SMA & 6 & 18,8 \\
Sarjana & 5 & 15,6 \\
\hline
\end{tabular}

Pada tabel 3 Menunjukkan bahwa upaya penangan pasien DM tipe 2 yang dilakukan oleh petugas kesehatan terhadap 32 pasien penderita DM tipe 2 di Puskesmas Bara-Baraya masih kurang $(100 \%)$. Tidak ada pasien pasien yang mendapatkan upaya penanganan cukup mengenai edukasi DM dan perencanaan makan. Hanya dua pasien yang mendapatkan upaya penanganan yang cukup mengenai aktivitas fisik. Untuk upaya penanganan mengenai obat $(\mathrm{OHO})$, semua pasien mendapatkan upaya penanganan yang cukup. Berdasarkan hasil pengamatan peneliti, pasien yang datang tersebut bukan karena mereka tidak mau mendapatkan penyuluhan/konsultasi gizi akan tetapi adanya keterbatasan waktu. Hal ini disebabkan jumlah tenaga kesehatan yang sedikit tidak sebanding dengan jumlah pasien yang banyak datang berobat ke puskesmas setiap harinya. Di Puskesmas Bara-Baraya terdapat 2 dokter (termasuk kepala puskesmas). Setiap hari, terdapat 2 dokter yang menangani pasien di poli. Sedangkan 2 dokter lainnya bertugas untuk turun ke lapangan untuk menangani pasien di pustu (puskesmas pembantu). Di Puskesmas Bara-Baraya terdapat POZI (Pojok gizi), namun pelayanan ini hanya diperuntukkan bagi bayi, balita, dan ibu hamil. Ini dikarenakan keterbatasan TPG (Tenaga pekerja gizi) yaitu 2 orang. Selain itu, TPG ini mempunyai tugas yang merangkap, yaitu selain melayani di POZI, juga turun ke posyandu-posyandu untuk memantau situasi gizi di masyarakat, menganalisa, serta mengintervensi jika terdapat kasus gizi buruk. Seperti penelitian yang dilakukan oleh Ptuteri dkk (2015) yang juga menemukan hambatan yang dialami petugas Puskesmas adalah dalam melakukan monitoring dan evaluasi hasil konseling. Hal ini disebabkan karena pasien yang melakukan kunjungan ulang masih rendah, selain itu fasilitas puskesmas terbatas seperti ruang konseling gizi dan food model. Pelayanan konseling gizi di puskesmas belum berjalan dengan baik, metode konseling yang digunakan masih konvensional serta belum didukung fasilitas yang memadai (14). 
Tabel 3. Distribusi Upaya Penanganan Diabetes Mellitus Tipe 2 di Puskesmas Bara-Baraya Kota Makassar

\begin{tabular}{|c|c|c|c|c|c|c|c|c|}
\hline \multirow{3}{*}{ Kategori } & \multicolumn{8}{|c|}{ Upaya Penanganan DM } \\
\hline & \multicolumn{2}{|c|}{ Edukasi DM } & \multicolumn{2}{|c|}{ Perencanaan Diet } & \multicolumn{2}{|c|}{ Aktivitas Fisik } & \multicolumn{2}{|c|}{ Intervensi Obat } \\
\hline & $\mathbf{n}$ & $\%$ & $\mathbf{n}$ & $\%$ & $\mathbf{n}$ & $\%$ & $\mathbf{n}$ & $\%$ \\
\hline \multicolumn{9}{|l|}{ Cukup } \\
\hline 3 poin & 0 & 0 & 0 & 0 & 2 & 6.25 & 32 & 100 \\
\hline \multicolumn{9}{|l|}{ Kurang } \\
\hline 2 poin & 0 & 0 & 3 & 9.4 & 17 & 53.1 & 0 & 0 \\
\hline 1 poin & 0 & 0 & 29 & 90,4 & 2 & 6.25 & 0 & 0 \\
\hline 0 poin & 32 & 100 & 0 & 0 & 11 & 34.4 & 0 & 0 \\
\hline
\end{tabular}

Pada tabel 4 menunjukkan bahwa pengetahuan pasien mengenai diabetes mellitus dengan kategori cukup yaitu 9 pasien $(28,1 \%)$ dan pasien yang memiliki pengetahuan yang kurang yaitu sebanyak 23 pasien $(71,9 \%)$. Sikap pasien mengenai DM tipe 2 dengan kategori positif yaitu 13 pasien $(40,6 \%)$ dan pasien yang memiliki sikap negative yaitu sebanyak 19 pasien (59,4\%). Sebanyak 25 pasien $(78,1 \%)$ tidak patuh terhadap jumlah kalori. Sebanyak 17 pasien $(53,1 \%)$ tidak patuh terhadap aktivitas fisik yang dianjurkan bagi penderita DM oleh petugas kesehatan, dan 18 pasien $(56,2 \%)$ tidak patuh minum obat sesuai yang dianjurkan petugas kesehatan. Perencanaan makan yang seharusnya dijelaskan kepada pasien penderita DM meliputi tepat jumlah kalori. Berdasarkan hasil pengamatan peneliti, penjelasan mengenai tepat jumlah kalori tidak pernah diberikan. Aktivitas fisik yang seharusnya dijelaskan kepada pasien penderita DM meliputi jenis aktivitas fisik, manfaat aktivitas fisik, frekuensi dan durasi aktivitas fisik. Berdasarkan hasil pengamatan peneliti dari ketiga hal tersebut, sebanyak 2 pasien $(6,25 \%)$ mendapat penjelasan yang cukup, sebanyak 17 pasien $(53,1 \%)$ mendapatkan penjelasan mengenai jenis dan durasi aktivitas DM, dan sebanyak 2 pasien $(6,25 \%)$ hanya mendapatkan penjelasan mengenai jenis aktivitas DM. Untuk penjelasan mengenai obat, seluruh pasien mendapatkan penjelasan yang cukup. Berdasarkan hasil penelitian diperoleh bahwa pengetahuan pasien mengenai diabetes mellitus masih sangat kurang. Dari total 32 pasien, hanya 9 pasien $(28,1 \%)$ yang memiliki pengetahuan yang cukup mengenai diabetes mellitus. Dari hasil wawancara, sebagian pasien yang memiliki pengetahuan cukup mengatakan bahwa informasi DM didapatkan dari poster yang dipajang di puskesmas, televisi, surat kabar, majalah atau orang lain. Banyaknya pasien yang memiliki pengetahuan kurang disebabkan kurangnya informasi atau pengetahuan mengenai diabetes mellitus yang juga disebabkan oleh upaya penanganan DM di puskesmas yang merupakan satu-satunya tempat berobat pasien DM di wilayah Puskesmas Bara-Baraya tidak terlaksana dengan maksimal. Hasil penelitian menunjukkan bahwa sikap pasien mengenai diabetes mellitus dengan kategori negatif lebih banyak $(59,4 \%)$ daripada pasien yang memiliki sikap positif. Pemberian konseling gizi tidak cukup hanya dengan menyampaikan jenis makanan apa saja yang harus dikurangi serta olah raga yang cukup, tetapi juga harus mampu mengubah perilaku pasien tentang gaya hidup. Dalam mengubah kebiasaan pola makan pasien tentunya berkaitan dengan mengubah perilaku, pola hidup serta kehidupan sosial pasien (15). Sangat sulit bagi tenaga kesehatan primer dalam memotivasi pasien untuk mengubah pola hidup apalagi dengan rentan waktu yang sempit (16) .

Hasil penelitian ini menunjukkan bahwa hanya 29,1\% pasien patuh dalam mengkonsumsi jumlah kalori sesuai kebutuhan, sedangkan $78,1 \%$ pasien tidak patuh dalam mengkonsumsi jumlah kalori yang sesuai dengan kebutuhannya. Ketidakpatuhan ini terjadi disebabkan karena kurangnya pengetahuan atau belum pernah mendapatkan penyuluhan/edukasi mengenai jumlah kebutuhan kalori yang dibutuhkan. Ketidakpatuhan ini terjadi disebabkan karena mereka belum pernah mendapatkan penyuluhan mengenai jumlah kalori yang seharusnya mereka konsumsi sesuai dengan kebutuhan mereka. Banyaknya pasien yang tidak patuh anjuran aktivitas fisik pada penderita DM dikarenakan kurangnya pengetahuan mengenai aktivitas fisik yang dianjurkan bagi penderita DM. Sebagian pasien memiliki pengetahuan mengenai aktivitas fisik apa saja yang dapat dilakukan oleh penderita DM 
dimana informasi tersebut didapat dari leaflet, surat kabar, maupun dari orang lain yang juga menderita DM seperti pengaturan pola makan dan melakukan latihan jasmani (physical exercise) juga sering menjadi kendala bagi penyandang DM. Hal ini tersebut karena penyandang diabetes sering merasa tidak memiliki waktu untuk melakukan latihan jasmani, waktunya habis untuk kegiatan sehari-hari seperti bekerja di kantor atau mengurus rumah tangga, malas, sibuk, adanya penyakit lain seperti rematik (17). Pasien yang patuh minum obat dengan kadar gula darah terkontrol yaitu $43,8 \%$, sedangkan yang tidak patuh minum obat dengan glukosa darah tidak terkontrol yaitu 56,2\%. Kepatuhan ini sangat terkait erat dengan kedisiplinan pasien dalam menjaga kesehatannya agar tidak menjadi semakin buruk. Kepatuhan pasien dalam penelitian ini juga terkait dengan kesibukan pasien. Kesibukan karena pekerjaan atau halhal yang lain seringkali membuat mereka lupa atau terlambat untuk mengkonsumsi obat yang telah diresepkan oleh dokter. Pelayanan yang dilakukan di puskesmas adalah pelayanan kesehatan primer yaitu pelayanan kesehatan yang terjangkau, murah, mudah, praktis, dan sesuai dengan standar dasar upaya pengobatan di puskesmas. Pada dasarnya pelayanan yang dilaksanakan di puskesmas adalah lebih banyak bersifat promotif dan preventif yaitu mencegah terjadinya komplikasi yang lebih berat, dan kegiatan promotif yang juga berguna untuk merubah pola hidup bersih dan sehat.

Edukasi gizi yang seharusnya dijelaskan kepada pasien yaitu mengenai pengertian dari penyakit DM (khususnya bagi pasien baru), faktor risiko DM, dan komplikasi penyakit DM. Berdasarkan hasil pengamatan, tidak ada pasien yang pernah mendapatkan edukasi DM dari petugas kesehatan baik pasien baru ataupun pasien lama.

Tabel 4.

Distribusi Sampel Berdasarkan Variabel Penelitian Diabetes Mellitus Tipe 2 di Puskesmas Bara-Baraya Kota Makassar

\begin{tabular}{lcc}
\hline \multirow{2}{*}{ Variabel } & \multicolumn{2}{c}{ Jumlah Pasien } \\
\cline { 2 - 3 } & $\mathbf{n}$ & \% \\
\hline Pengetahuan DM & 9 & 28,1 \\
\hline Cukup & 23 & 71,9 \\
Kurang & & \\
\hline Sikap Terhadap DM & 13 & 40,6 \\
\hline Positif & 19 & 59,4 \\
Negatif & & 21,9 \\
\hline Kepatuhan Jumlah Kalori & 7 & 78,1 \\
\hline Patuh & 25 & 46,9 \\
Tidak Patuh & & 53,1 \\
\hline Aktivitas Fisik Pasien DM & 15 & \\
\hline Patuh & 17 & 43,8 \\
Tidak Patuh & & 56,2 \\
\hline Intervensi Obat & 14 & \\
\hline Patuh & 18 & \\
Tidak Patuh & & \\
\hline
\end{tabular}

Pada tabel 5 menunjukkan sebanyak 18 pasien memiliki glukosa darah tidak terkontrol $(56,2 \%)$, sedangkan pasien yang glukosa darahnya terkontrol yaitu 14 pasien $(43,8 \%)$. Jika dilihat, banyaknya pasien yang memiliki glukosa darah tidak terkontrol ini pada awalnya disebabkan oleh upaya penanganan DM di puskesmas yang masih kurang, yang berakibat terhadap kurangnya pengetahuan, sikap, dan tindakan (kepatuhan diet, kepatuhan aktivitas fisik, dan kepatuhan minum obat). Tingkat kesadaran yang baik dipengaruhi oleh pengetahuan masyarakat yang baik pula tentang diabetes mellitus tipe 2. Pengetahuan merupakan hal mendasar untuk menyadarkan masyarakat berperilaku sehat, sehingga deteksi dini dari gejala yang di timbulkan akan diketahui. Deteksi dini diabetes melitus adalah tindakan awal sebagai upaya kemungkinan terkena diabetes melitus secara dini agar dapat ditangani secara memadai, sehingga kesakitan/komplikasi dapat dicegah (18). 
Tabel 5.

Distribusi GDS Terkontrol Pasien Diabetes Mellitus Tipe 2 di Puskesmas Bara-Baraya Kota Makassar

\begin{tabular}{ccc}
\hline \multirow{2}{*}{ Glukosa Darah } & \multicolumn{2}{c}{ Jumlah Pasien } \\
\cline { 2 - 3 } & $\mathbf{n}$ & $\mathbf{0}$ \\
\hline Terkontrol & 14 & 43.8 \\
Tidak terkontrol & 18 & 56.2 \\
\hline Total & $\mathbf{3 2}$ & $\mathbf{1 0 0}$
\end{tabular}

Penyakit diabetes melitus ini dapat mempengaruhi kualitas hidup, diantaranya: (1) Adanya tuntutan terus-menerus selama hidup penderita terhadap perawatan DM, seperti pembatasan atau pengaturan diet, monitoring gula darah, pembatasan aktifitas (2) Gejala yang timbul ketika kadar gula darah turun ataupun sedang tinggi (3) ketakutan akibat adanya komplikasi yang menyertai, (4) disfungsi seksual. Adapun aspek lain yang mempengaruhi kualitas hidup pasien diabetes mellitus adalah lama menderita diabetes mellitus(19).

\section{Kesimpulan}

Upaya penanganan pasien penderita DM tipe 2 di Puskesmas Bara-Baraya masih kurang maksimal. Masih banyak pasien tidak mendapatkan penyuluhan terkait 4 pilar penanganan DM. Penelitian ini menyarankan agar edukasi kepada pasien DM dapat dilaksanakan agar pasien dapat mengetahui penatalaksanaan diabetes mellitus secara tepat dan benar serta dapat merawat dirinya secara mandiri. Kepada Puskesmas, disarankan untuk lebih memaksimalkan peran TPG dalam pelayanan di POZI. Sebaiknya pelayanan di POZI tidak hanya diperuntukkan untuk bayi, balita ataupun ibu hamil saja, tetapi juga difungsikan untuk melayani pasien penderita penyakit lain, khususnya pasien penderita DM.

\section{Daftar Pustaka}

1. Report NDS. National Diabetes Statistics Report. 2020. Natl Diabetes Stat Rep. 2020;2. https://www.cdc.gov/diabetes/data/statistics-report/index.html

2. Nam Han Cho (chair) et al. IDF Diabetes Atlas, 8th edition. 2017.1-150 p. https://diabetesatlas.org/upload/resources/previous/files/8/IDF_DA_8e-EN-final.pdf

3. Mansbridge J. Skin substitutes to enhance wound healing. Expert Opin Investig Drugs. 1998;7(5):803-9.

4. Ligita T, Wicking K, Francis K, Harvey N, Nurjannah I. How people living with diabetes in Indonesia learn about their disease: A grounded theory study. PLoS One. 2019;14(2):1-19.

5. Dinas Kesehatan Provinsi Sulawesi. Prevalensi Penderita Diabetes Mellitus Kota Makassar 2012. Makassar, Sulawesi Selatan.

6. Kota DKM. Laporan Tabunan Dinas Kesehatan Kota Makassar Tabun 2012. Makassar. 2012. https://pusdatin.kemkes.go.id/resources/download/profil/PROFIL_KES_PROVINSI_2012/2 6_Profil_Kes.Prov.SulawesiSelatan_2012.pdf

7. Soelistijo S, Novida H, Rudijanto A, Soewondo P, Suastika K, Manaf A, et al. Konsensus Pengelolaan Dan Pencegahan Diabetes Melitus Tipe2 Di Indonesia 2015. Perkeni. 2015. 82 p.

8. Soegondo S, dkk. 2010. Buku Panduan Penatalaksanaan Diabetes Mellitus di Layanan Kesehatan Primer di Indonesia. Departemen Ilmu Kedokteran Komunitas. Fakultas Kedokteran Universitas Indonesia, Jakarta.

9. Faizia I-M. 2009. Evaluasi Pelaksanaan Konsultasi Giri Dengan Standar Diet Terbadap Pengetahuan, Perilaku Makan dan Kadar Glukosa Darah Pasien Diabetes Mellitus Tipe 2 Rawat Jalan di RSUD Untada Palu Tabun 2009. Skripsi Sarjana. Universitas Tadulako, Palu.

10. Sale A-Z-M. 2010. Studi Pengetahuan, Diet, Aktivitas Fisik, Minum Obat, dan Kadar Glukosa Darah Pasien Dm Tipe 2 Sebelum dan Setelah Pendampingan Giri di Puskesmas Baula Kabupaten Kolaka. Skripsi 
Sarjana. Fakultas Kesehatan Masyarakat. Universitas Hasanuddin, Makassar.

11. Rahmawati. 2011. Hubungan Pola Makan dan Aktvitas Fisik dengan Kadar Glukosa Darah Penderita Diabetes Mellitus Tipe 2 Rawat Jalan di Poli Endokrin RSUP DR W abidin Sudirohusodo Makassar. Skripsi Sarjana. Fakultas Kesehatan Masyarakat. Universitas Hasanuddin, Makassar.

12. Sutiawati M. 2012. Pengarub Edukasi Gizi Terhadap Tingkat Pengetahuan, Pola Makan, dan Kadar Glukosa Darab Pada Pasien Diabetes Mellitus Tipe 2 Di RSUD Lanto Dg. Pasewang Kabupaten Jeneponto. Skripsi Sarjana. Fakultas kesehatan Masyarakat. Universitas Hasanuddin, Makassar.

13. Hamid S-T-K. 2012. Pengaruh Edukasi Gizi Terhadap Peningkatan Pengetahuan, Kepatuhan Diet dan Kadar Glukosa Darah Pasien Diabetes Mellitus Tipe 2 Rawat Jalan Puskesmas Jumpandang Baru Kota Makassar Tahun 2012. Skripsi Sarjana. Fakultas kesehatan Masyarakat. Universitas Hasanuddin, Makassar.

14. Zahra P-F, Diah D-M, Miftahurachman M. 2016. Gambaran Pelayanan Konseling Gizi pada Pasien Diabetes Mellitus Tipe 2 di Puskesmas Jatinangor Tabun 2015. J Sist Kesehat. 2016;1(4):186-92.

15. Jansink R, Braspenning J, Weijden T-V-D, Elwyn G, Grol R. 2010. Primary care nurses struggle with lifestyle counseling in diabetes care: a qualitative analysis. BMC Family Practice 2010, 11:41.

16. Jafar N, Indriasari R, Syam A, Kurniati Y, Bohari. The Effect Of Educator Training On Students Knowledge Of Balanced Nutrition In Makassar, Indonesia. International Journal of Medical Science and Clinical Invention 5(05): 3838-3843, 2018.

17. Astri Z, Priyadi N, Ratih I. Faktor - Faktor Yang Berbubungan Dengan Kepatuban Aktivitas Fisik Penderita Dm Untuk Pencegahan Komplikasi Di Wilayah Kerja Puskesmas Rowosari Kota Semarang. J Kesehat Masy. 2019;7(1):453-61.

18. Limsah S. Hubungan Pengetahuan dan Tindakan Pencegahan Diabetes Mellitus Tipe 2. Jurnal Promkes: The Indonesian Journal of Health Promotion ad Health Education Vol. 7 No. 2, 2019. 223-232 doi: 10.20473/jpk.V7.I2.2019.223-232.

19. Fitri S, Daryani, Marwanti, Danang A. Penatalaksanaan 5 Pilar Pengendalian DM Terhadap Kualitas Hidup Pasien DM Tipe 2. Jurnal Ilmiah Permas: Jurnal Ilmiah STIKES Kendal Volume9 No 4 Oktober 2019, Hal 311-318. 